\title{
Un análisis socio-metafórico del discurso mediático de la Gran Recesión en La Vanguardia
}

José Luis Martín Sáez| joseluis.martin.saez@urjc.es

Universidad Rey Juan Carlos

Manuel Montes Vozmediano | manueljavier.montes@urjc.es

Universidad Rey Juan Carlos

Palabras clave

"Crisis"; "Metáfora"; "Humanitario"; "Discurso mediático"; "La Vanguardia".

Sumario

1. Introducción.

1.1. La construcción del relato periodístico sobre la crisis.

1.2. El lenguaje metafórico.

2. Metodología.

3. Resultados.

4. Discusión.

5. Conclusiones.

6. Bibliografía.

\section{Resumen}

Este trabajo de investigación analiza, desde una perspectiva socio-metafórica, el relato periodístico del diario de referencia en Cataluña, La Vanguardia, a la hora de contar la crisis iniciada en 2008, conocida como la Gran Recesión. El objetivo es conocer cómo se ha elaborado el relato mediante el cual el periódico narra a su audiencia la representación de una realidad cuyo impacto trascendió el factor económico y tuvo repercusiones en todas las esferas del individuo y la sociedad. Mediante la metodología del análisis de contenido se ha estudiado el relato, tanto informativo como de opinión, de dicho diario. El sustento de la investigación ha sido el registro y análisis de las metáforas empleadas por La Vanguardia. El estudio concluye que las metáforas empleadas permiten hablar de un rescate del sistema bancario español por razones humanitarias y la relevancia de su empleo se fundamenta en que aparecen en epígrafes destacados como los titulares o los sumarios.

\section{Cómo citar este texto:}

José Luis Martín Sáez, Manuel Montes Vozmediano (2019): Un análisis socio-metafórico del discurso mediático de la Gran Recesión en La Vanguardia, en Miguel Hernández Communication Journal, n¹0 (1), pp. 83 a 99. Universidad Miguel Hernández, UMH (Elche-Alicante). DOI: http://dx.doi.org/10.21134/mhcj.v10i0.276 


\title{
A socio-metaphorical analysis of the media discourse of the Great Recession in La Vanguardia
}

José Luis Martín Sáez| joseluis.martin.saez@urjc.es

Universidad Rey Juan Carlos

Manuel Montes Vozmediano| manueljavier.montes@urjc.es

Universidad Rey Juan Carlos

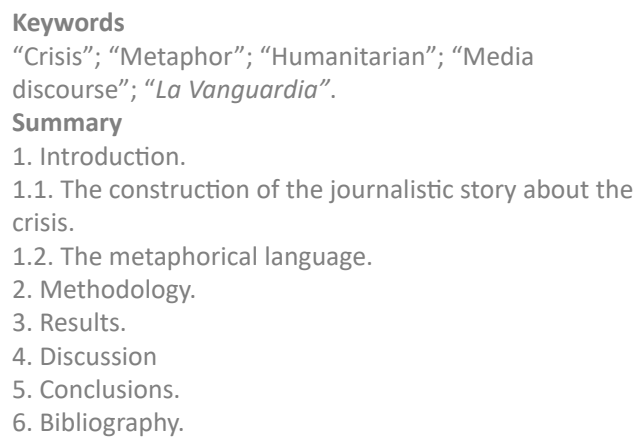

\begin{abstract}
This research analyzes, from a socio-metaphorical perspective, the journalistic narrative used by the newspaper of reference in Catalonia, La Vanguardia, to expose its readers to the events of the Great Recession, the crisis that began in 2008. The objective is to know how the story has been elaborated through which the newspaper exposes to your audience the representation of a reality whose relevance transcended the economic
\end{abstract} factor and had repercussions in all areas of the individual and society. Through the methodology of content analysis has studied the story, both informative and opinion, of this newspaper. The base of the investigation has been the annotation and analysis of the metaphors used by La Vanguardia.The work concluded that the metaphors used by it allow us to speak of a rescue of the Spanish banking system for humanitarian reasons and the importance of its use is based on its inclusion in prominent textual elements such as headlines or summaries.

\section{How to cite this text:}

José Luis Martín Sáez, Manuel Montes Vozmediano (2019): A socio-metaphorical analysis of the media discourse of the Great Recession in La Vanguardia, in Miguel Hernández Communication Journal, nº10 (1), pp. 83 a 99. Universidad Miguel Hernández, UMH (Elche-Alicante). DOI: http://dx.doi.org/10.21134/mhcj. $\underline{\mathrm{v} 10 \mathrm{i} 0.276}$ 


\section{Introducción}

Casi cuatro años después de la quiebra del banco de inversión estadounidense Lehman Brothers, que supuso el pistoletazo de salida a la mayor crisis económica sufrida por el mundo occidental desde la Gran Depresión de 1929, la palabra riesgo cobraba un nuevo significado, bajo el marco conceptual de una sociedad bautizada en 1986 como "del riesgo" por el sociólogo alemán Ulrich Beck (1996). La Real Academia Española (RAE) aprobaba en junio de 2012 la incorporación a su diccionario de una nueva acepción de la palabra riesgo: "Incertidumbre para un inversor o entidad financiera, derivada de que los cambios que se producen en los mercados alteren el precio de sus activos" (Diccionario en línea de la RAE).

Un nuevo significado para la palabra riesgo, enmarcado en una sociedad en la que el hombre, según Ulrich Beck, debe entender su vida "como estando sometida a los más variados tipos de riesgo, los cuales tienen un alcance personal y global” (Beck, 1996: 205).

Al fin y al cabo, la caída del cuarto banco de inversión del mundo no solo suponía la bancarrota del mismo, sino también la quiebra de algo más abstracto, de un bien intangible, el concepto lineal del progreso y de su inevitabilidad intrínseca. "Si la idea de progreso en su forma actual nos resulta tan poco familiar que uno se pregunta si aún está entre nosotros, es porque el progreso, como tantos otros parámetros de la vida moderna, ha sido 'individualizado'; lo que es más: desregulado y privatizado" (Bauman, 2013: 144).

Palabras y conceptos como prima de riesgo, deuda soberana o rescate bancario se incorporaban a nuestra vida diaria, a nuestro vocabulario, a través del relato mediático sobre la crisis. Porque, como decía Niklas Luhmann, "lo que sabemos del mundo, lo advertimos a través de los medios de comunicación” (Luhmann, 2007:1). Unos medios que dieron una amplia cobertura a la crisis pero en los que no tuvo cabida un proceso crítico que cuestionara la pertinencia del sistema (Prieto-Pradas, 2013).

Unos medios que, como además, según la teoría del framing, pueden ser capaces de decirnos no solo sobre qué pensar sino también cómo pensar (Valkenburg, Semetko y de Vrees, 1999: 567), son clave a la hora de la formación de la opinión pública, en este caso, sobre la crisis y sus consecuencias. Sin olvidar que "lo que consideramos natural, inevitable, bueno o verdadero puede no serlo [...] las cosas dadas de nuestra vida están influidas por fuerzas históricas y sociales" (Giddens, 2000: 29).

\subsection{La construcción del relato periodístico sobre la crisis}

Porque ¿cuál fue el relato mediático que sobre la Gran Recesión construyeron los medios? ¿Cómo nos narraron la crisis? Estas son las preguntas de investigación en este estudio en el que hemos puesto el foco en La Vanguardia, el diario de mayor difusión en Cataluña y el tercero a nivel nacional (OJD, 2018), con el fin de conocer cuál fue el discurso que construyó dicho periódico sobre la Gran Recesión, a partir del lenguaje empleado en los relatos que aparecieron en sus páginas.

Unos relatos que, según Roberto Herrscher (2012), serían producto de un periodismo que es cada vez más narrativo y menos descriptivo. Una forma de hacer periodismo que hace del "cómo", una de las preguntas a las que debe contestar todo mensaje periodístico y que consiste en contar cómo pasaron las cosas, su base fundamental. "El cómo [...] es una invitación para el 
que quiera o pueda adentrarse en el relato de los hechos y sacar de allí información que le sirva para reflexionar sobre otros temas [...]. En este [...] nivel los datos no agregan información, sino que ayudan a comprender, recordar, dar sentido a lo que pasó" (Herrscher, 2012: 51).

De modo que en el caso que nos ocupa, se trataría de comprender, recordar y dar sentido a la Gran Recesión, a partir del lenguaje utilizado en la narración de la misma y, más concretamente, de las metáforas empleadas en dicho relato. Porque el lenguaje crea realidad y "es lo que se dice, pero también lo que destierra" (Serrano, 2009: 61). Porque las metáforas destacan unos aspectos de la realidad, ocultando otros (Lakoff y Johnson, 2012). Un lenguaje, por tanto, que no sería aséptico sino todo lo contrario, porque "la ideología impregna el lenguaje de muchas maneras, y no es la menor la elaboración metafórica: todo el discurso económico y sociológico dibuja un universo de causalidades, de fluidos y circuitos de reparto que conviene desbrozar para comprender, primero, que la existente no es la única forma de hablar de las cosas, y segundo, que en cuanto hablamos 'de otra forma' gran parte de las categorías, de las causas y de los efectos que manejamos de forma natural se diluirían hasta la desaparición" (Millán y Narotzky, 2012: 25).

Una ideología que, en este caso, utiliza el lenguaje para contar la crisis como una lingua franca. Una lengua que buscaría convertirse en la única que permitiera entender la crisis y sus consecuencias, a partir del léxico generado por los medios de comunicación a propósito de este hecho.

Y teniendo en cuenta que "se empieza por ceder en las palabras y se acaba a veces por ceder en las cosas" (Freud, 2015: 35), el resultado sería el de un discurso mediático que ha permitido contar algo tan complejo como la Gran Recesión de forma sencilla, a través del uso metafórico del lenguaje. Porque no podemos olvidar que "nosotros no construimos las historias o, mejor, no somos autores de su sentido: este viene dado y muy acotado, para que no lo forcemos o cambiemos" (Roig, 2008: 13). Y es que hablamos del poder del discurso y del poder como tal: "Lo que hace que el poder se sostenga, que sea aceptado, es sencillamente que no pesa solo como potencia que dice no, sino que cala de hecho, produce cosas, induce placer, forma saber, produce discursos" (Foucault, 2000: 137).

Un poder que, en definitiva, utiliza el discurso atendiendo "tanto al contexto como a las propias estructuras del texto y del habla" (Dijk, 2009: 167), con el objetivo de legitimar una determinada representación de la realidad a través del lenguaje, en este caso, metafórico.

El objetivo de este estudio ha sido registrar las metáforas empleadas por La Vanguardia y gracias a ellas entender la construcción de la representación de la realidad que trasmitió dicho periódico a la audiencia.

\subsection{El lenguaje metafórico}

El lenguaje metafórico es uno de los recursos de la denominada nueva retórica, un arte que constituye el marco general bajo el que analizamos los textos periodísticos que forman parte de este trabajo. Una nueva retórica que utiliza los recursos de la lengua de tal modo "que los argumentos resulten razonables y alcancen así a movilizar la sensibilidad necesaria que venga a salvar la brecha de credibilidad a que aspiran los discursos dominantes para ser percibidos como legítimos" (Lizcano, 1999: 86-87). 
Y así, bajo este enfoque, es donde entra en juego la metáfora. Una figura retórica donde se asientan tanto el razonamiento matemático como el no matemático de la economía: "Cada paso que se dé en el razonamiento económico, incluso el razonamiento de la retórica oficial, es metafórico" (McCloskey, 1990: 106-111).

En este sentido, la metáfora habría sido uno de los recursos utilizados por los medios de comunicación en su narrativa sobre la crisis, para tratar de convencer y persuadir a la audiencia acerca de cómo percibir la misma, porque "desde los comienzos de la retórica se sabe que las emociones desempeñan un papel importante en la comunicación y la argumentación” (Bustos, 2014: 104). Unas emociones a las que, precisamente, la metáfora apela, y que nos llevarían a percibir la Gran Recesión y sus consecuencias de una determinada manera.

En consecuencia, nos acercamos hasta los textos de nuestra investigación desde un punto de vista sociológico, realizando un análisis socio-metafórico del lenguaje que emplearon a la hora de hablar de la crisis. Porque las metáforas organizan los discursos, "estructurando su lógica interna y [...] sus contenidos" (Lizcano, 1999: 29). Se trata de un estudio cualitativo que parte de la premisa de que "todo concepto es metafórico y, por tanto, concepto social" (Lizcano, 1999: 31).

Porque, según Emmánuel Lizcano, todos los conceptos científicos nacen como metáforas. Metáforas que se rebaten, se defienden y se trasladan de unas disciplinas a otras, poniendo en evidencia la experiencia de quien las enuncia. Alguien que, por otro lado, es un ser social, y que construirá conceptos y articulará un discurso, seleccionando unas metáforas y desechando otras, en función de una serie de factores culturales, intereses o de quién sea el destinatario de dicho discurso (1999: 30-32).

Y dicho esto, y teniendo en cuenta que "la esencia de la metáfora es entender y experimentar un tipo de cosa en términos de otra” (Lakoff y Johnson, 2012: 41), a la hora de analizar las informaciones periodísticas, entenderemos como metáforas "aquellas imágenes que suponen la aplicación de un concepto de un campo de origen a otro diferente, sin distinguir entre metáforas propiamente dichas, metonimias, símiles o personificaciones" (Gallego, 2013: 2).

\section{Metodología}

En este trabajo de investigación se ha empleado la metodología del análisis de contenido, puesto que se basa en el empleo de "procedimientos sistemáticos y objetivos de descripción del contenido de los mensajes” (Bardin, 1996:29). La aplicación del conjunto de técnicas que configuran esta metodología se considera idónea para el estudio de los mensajes difundidos por los medios de comunicación (Krippendorff, 1990; Igartua, 2006) e igualmente adecuada para el análisis de mensajes textuales o de otra índole.

Se sigue la línea de análisis de otros estudios que se ocupan de la plasmación en prensa de situaciones de crisis como el de Clara de Uribe, Núria Arimany y Anna Sabata-Aliberch (2016), que se centran en la crisis de la empresa Abengoa y el fenómeno de las denominadas "puertas giratorias" o el de José Luis Martín Sáez (2015) que aborda la crisis económica. Sin olvidar estudios de discursos como el de Antonio Gaspar y Nieves Ibeas (2015) que analizaron el Mensaje de Navidad de Su Majestad el Rey emitido en diciembre de 2012, en pleno periodo de crisis, y en el que también aparecen metáforas morales como "sacrificio". 
En este análisis, el objeto de estudio son las informaciones y los editoriales publicados en la edición impresa del diario La Vanguardia sobre la crisis iniciada en 2008 y sus consecuencias. El período de tiempo analizado es representativo y simbólico, puesto que comienza el 17 de mayo de 2012, al día siguiente de que la prima de riesgo española alcanzase los 500 puntos básicos de diferencia con el bono alemán, y termina el 26 de junio de ese mismo año, una jornada después de que el Gobierno español solicitara oficialmente ayuda financiera a la Unión Europea para su sistema bancario. Cabe recordar aquí que los países rescatados hasta ese momento, Grecia, Irlanda y Portugal, solicitaron ayuda económica a la Unión Europea con una prima de riesgo de 580, 512 y 658 puntos básicos, respectivamente.

La unidad de análisis de esta investigación coincide con la pieza periodística, ya sea informativa o de opinión. En cada unidad de análisis se van a analizar los diferentes epígrafes textuales que puede contener: antetítulos, títulos, subtítulos, entradillas, ladillos, sumarios, cintillos, pies de foto y destacados de las informaciones y editoriales aparecidos en la edición en papel de $L a$ Vanguardia, sobre la crisis española y sus consecuencias, durante el periodo ya reseñado. Se excluye el cuerpo de texto ya que crearía redundancias en los resultados cuantitativos.

La selección de los epígrafes textuales mencionados se basa en la investigación de Manuel Montes Vozmediano (2013) que considera dichos epígrafes como los elementos textuales de referencia a la hora de estudiar los mensajes periodísticos de las publicaciones periódicas. La única diferencia es que en esta investigación se agrupan en una única categoría denominada destacados, aquellos contenidos de refuerzo que pueden acompañar una misma información (como cuadros de apoyo o fichas) y que el mencionado investigador separa, a su vez, en diferentes categorías, ya que persigue diferenciarlos por su naturaleza formal (diseño), algo que no se persigue en este caso.

Por otra parte, el análisis socio-metafórico toma como referencia primigenia las categorías definidas por Emmánuel Lizcano (2009) en relación a los discursos sobre la crisis difundidos por los medios de comunicación. Categorías bajo las que distinguía entre metáforas de naturalización, médicas y de fetichización. Se ha partido de la propuesta de Lizcano y se ha tenido en consideración la más reciente de José Luis Martín Sáez (2015) que incrementaba el número de tipologías metafóricas, segmentando el apartado fetichización enunciado por aquél. Tras el análisis de los epígrafes textuales que forman el corpus de este trabajo, hemos identificado las siguientes categorías metafóricas:

Tabla 1. Tipología de las metáforas de la crisis.

\begin{tabular}{|l|l|}
\hline TIPOLOGÍA & DEFINICIÓN \\
\hline METÁFORAS ALARMANTES O APOCALÍPTICAS & Bajo la categoría de metáforas alar- \\
mantes o apocalípticas hemos clasi- \\
ficado aquellas cuya narración de la \\
crisis connota temor o es percibida \\
como una gran amenaza, llegando a \\
utilizar imágenes que evocan el fin \\
del mundo.
\end{tabular}




\begin{tabular}{|l|l|}
\hline METÁFORAS BÉLICAS & $\begin{array}{l}\text { Alrededor de esta denominación } \\
\text { hemos agrupado todas aquellas fi- } \\
\text { guras que utilizan términos propios } \\
\text { de la guerra o conflicto bélico, para } \\
\text { contar la crisis. }\end{array}$ \\
\hline METÁFORAS HUMANITARIAS & \\
\hline METÁFORAS SANITARIAS & $\begin{array}{l}\text { Alrededor de las metáforas humani- } \\
\text { tarias, hemos seleccionado aquellas } \\
\text { que al narrar la crisis hacen referen- } \\
\text { cia "al bien del género humano" } \\
\text { (Diccionario en línea de la RAE). }\end{array}$ \\
\hline $\begin{array}{l}\text { Las metáforas médicas son aquellas } \\
\text { que han presentado "el sistema } \\
\text { económico como un paciente } \\
\text { cuyos órganos (sistema financiero, } \\
\text { mercados, empresas, entidades de } \\
\text { crédito...) se ven aquejados de las } \\
\text { más variadas patologías" (Lizcano, } \\
\text { 2009: 91), y a quien hay de sanar de } \\
\text { alguna manera. En este trabajo se } \\
\text { emplea la definición de Lizcano, si } \\
\text { bien se cambia el término "médi- } \\
\text { cas" por "sanitarias", al ser una voz } \\
\text { más genérica. }\end{array}$ \\
\hline METÁFORAS MORALES & $\begin{array}{l}\text { Las metáforas morales hablan de } \\
\text { uno de los tópicos más utilizados } \\
\text { por la retórica: la justicia poética. } \\
\text { Esa razón que, convertida en ley } \\
\text { natural, consiste en premiar la } \\
\text { virtud y castigar el vicio, en recom- } \\
\text { pensar los buenos comportamien- } \\
\text { tos y penar las malas prácticas, en } \\
\text { este caso, los números rojos en las } \\
\text { cuentas de la economía española. }\end{array}$ \\
\hline $\begin{array}{l}\text { Bajo la denominación de natura- } \\
\text { lización hemos incluido aquellas } \\
\text { metáforas que "construyen la } \\
\text { percepción de la crisis' como si de } \\
\text { un fenómeno de la naturaleza se } \\
\text { tratara" (Lizcano, 2009: 91). }\end{array}$ \\
\hline
\end{tabular}




\begin{tabular}{|l|l|}
\hline METÁFORAS DE PERSONIFICACIÓN & $\begin{array}{l}\text { En torno a la categoría de perso- } \\
\text { nificación, hemos ordenado todas } \\
\text { aquellas metáforas que, a la hora de } \\
\text { relatarnos la crisis, han dotado a los } \\
\text { diferentes componentes y estruc- } \\
\text { turas del sistema económico de } \\
\text { características propias de los seres } \\
\text { humanos. }\end{array}$ \\
\hline METÁFORAS DE PLANO GENERAL & $\begin{array}{l}\text { Metáforas que sirven para transmi- } \\
\text { tir una impresión de localización de } \\
\text { ambiente, evocando una imagen, un } \\
\text { paisaje o un escenario de la crisis. }\end{array}$ \\
\hline
\end{tabular}

Otras variables que se tendrán en cuenta, además de las estrictamente registrales (como la fecha de publicación, la página, la anotación del epígrafe textual literal y el medio, en este caso, La Vanguardia) serán:

- El número de la información. De este modo se podrá saber qué cantidad de unidades periodísticas incluyeron una voz metafórica.

- La sección. Lo que nos permitirá conocer en qué apartados del periódico tenían cabida las metáforas.

- El género periodístico. Se ha distinguido entre dos categorías (información y opinión). En el caso de las inserciones de opinión se ha registrado si se trataba de una opinión firmada o un editorial.

- La categoría metafórica. Según la clasificación mencionada con anterioridad, podremos conocer las categorías más utilizadas.

- La voz metafórica. Es decir, el término concreto (por ejemplo, “inyección”) que posibilitará elaborar un listado de las voces metafóricas empleadas por el medio.

- El epígrafe textual en el que aparece la voz metafórica. Según la clasificación de Manuel Montes Vozmediano (2013), que permitirá conocer en qué lugar de la unidad informativa aparecen las voces metafóricas.

En una misma unidad de análisis pueden aparecer distintas voces metafóricas (en un mismo título puede haber más de una o computando varios epígrafes, aparecer varias). Todas ellas serán registradas. De la misma manera, si en una misma unidad de análisis aparece varias veces una misma voz metafórica (por ejemplo, en el título y también en el sumario) también serán anotadas. Si bien a efectos totales no se duplicará el número de veces en que aparece la voz metafórica (una misma voz metafórica se computará una sola vez, aunque aparezca varias veces en la misma unidad de análisis), a efectos de presencia en los epígrafes textuales, sí se computará este registro múltiple.

\section{Resultados}

El periodo analizado se compone de 41 jornadas (desde el jueves 17 de mayo al martes 26 de junio de 2012). Sólo en cuatro días no aparece ninguna voz metafórica en ese periodo de tiempo, es decir, el empleo de este tipo de recursos por parte de La Vanguardia es frecuente (se produce en el 90\% de los casos). 
Figura 1. Presencia de voces metafóricas en el periodo analizado.

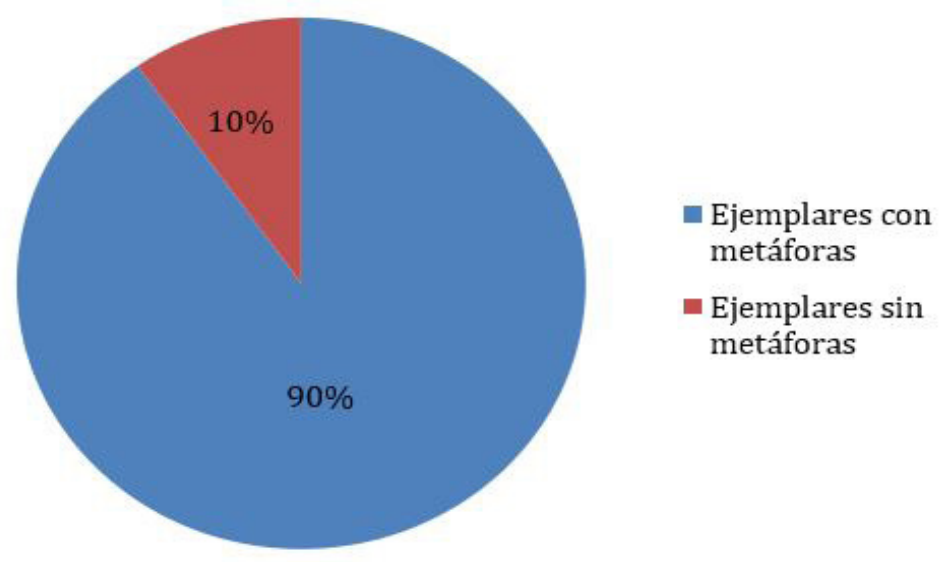

La unidad de análisis de la investigación es la pieza periodística. Se han localizado 139 piezas con, al menos, una metáfora, de modo que la media resultante del periodo analizado es de más de tres piezas metafóricas al día. En dos ocasiones, en un único ejemplar, se alcanza o se supera la decena de piezas periodísticas (ya sean informativas u opinativas) con alguna voz metafórica. No obstante, la cifra de voces metafóricas registradas (172) es mayor que el número de piezas periodísticas (139), ya que en una misma pieza pueden aparecer distintas voces metafóricas.

Si nos atenemos al género periodístico, 123 pertenecen al ámbito de la información y 16 al de la opinión (11 de ellas son opiniones con firma, mientras que las otras cinco se han hallado en editoriales del medio).

La distribución de las piezas metafóricas según la categoría es dispar, tal y como puede apreciarse en la figura 2. En primer lugar, sobresale la categoría de las metáforas humanitarias, que con 86 casos (de un total de 172) acapara el 50\%. En segundo lugar, se sitúan las voces metafóricas sanitarias con 32 casos (18.6\%), seguidas de las alarmantes o apocalípticas con 24 (14\%).

Figura 2. Distribución de las categorías metafóricas. Fuente: Elaboración propia..

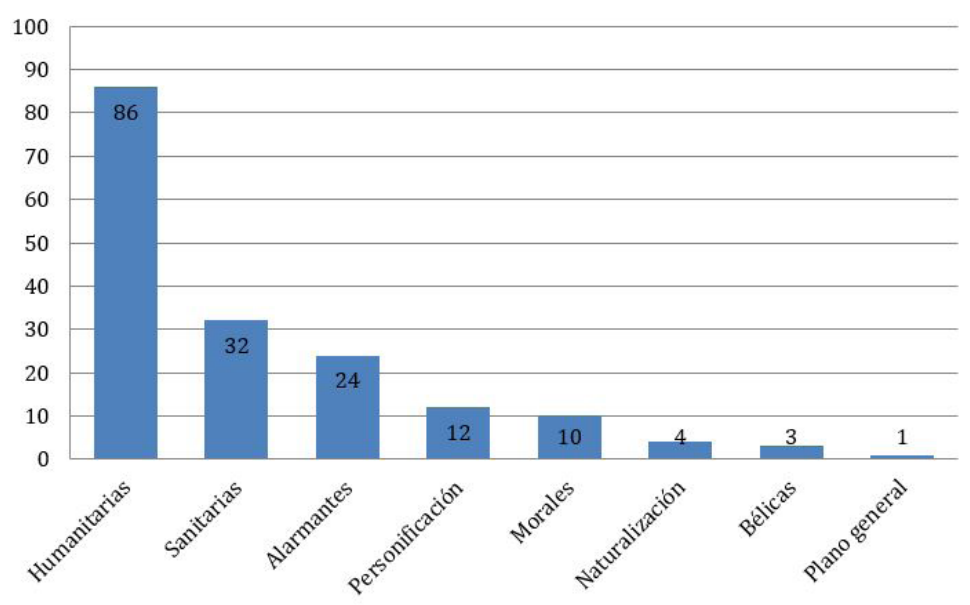


Se aprecia pues que la tendencia a la hora de hablar de la crisis es que nos enfrentamos a una cuestión humanitaria. Según el diccionario de la Real Academia (DRAE, 2012), humanitaria hace referencia "al bien del género humano". Y al bien del género humano nos referiremos cuando hablemos de "rescate", en este caso, cuando hablemos del rescate del sistema bancario español.

Tras la categoría de metáforas humanitarias, destaca el empleo, por el diario La Vanguardia, de metáforas sanitarias. La Gran Recesión es también, por tanto, una cuestión de salud, el sistema económico español está enfermo, y como tal debe ser sometido a distintos tratamientos ("recortes"), para su recuperación. Cuando se abandona esta metáfora el siguiente recurso, a tenor de los resultados, muestra un panorama alarmante de la situación con unas expectativas pesimistas. La suma de las categorías metafóricas humanitarias, sanitarias y alarmantes o apocalípticas aglutina 136 registros (el 79\% del total de metáforas encontradas). Otras categorías que alcanzan, al menos, los diez casos son las metáforas de personificación (12 casos; 7\%) y las morales (10 casos; $5.8 \%$ ).

En relación a la ubicación de la metáfora, el título de la información es el epígrafe textual en el que, con mayor frecuencia, aparece una voz metafórica (véase la figura 3). De los 172 casos registrados, en 93 de ellos (54\%) la voz metafórica aparece en el título. En segundo lugar, se recurre a los sumarios (con 48 casos; $27.9 \%$ ) mientras que el resto de los epígrafes textuales no alcanza tan siquiera un 10\% de representatividad: subtítulo (15), antetítulo (7), destacado (4), pie de foto (3) y ladillo (2). No se ha encontrado ni un solo caso de voz metafórica ni en las entradillas ni en los cintillos.

Así pues, títulos y sumarios acaparan más del $80 \%$ de los registros y se configuran como los elementos textuales más representativos a la hora de trasladar las voces metafóricas divulgadas por el medio. La audiencia de los diarios tiende a ojear la página y a detenerse en los epígrafes destacados pues constituyen llamadas de atención y son resúmenes del texto noticioso (Galán, 2001), de modo que la presencia de las metáforas en estos epígrafes nos da una idea de la relevancia que el medio otorga a su inclusión.

Figura 3. Epígrafes textuales con categorías metafóricas. Fuente: Elaboración propia..

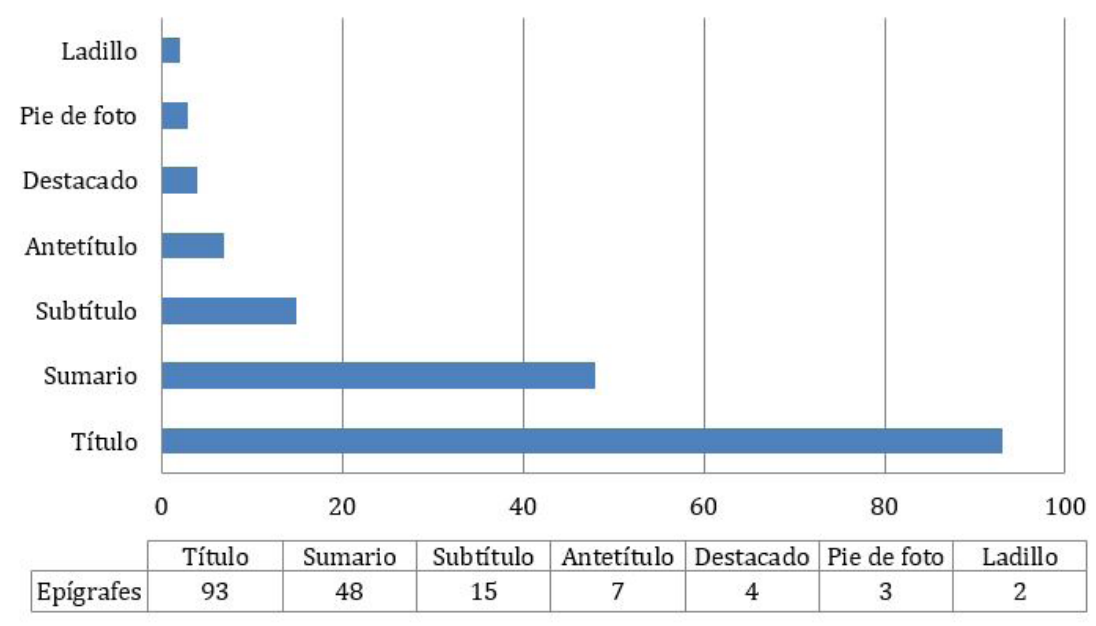


Como se puede apreciar en la tabla 2, la pauta general se aplica con un protocolo idéntico en las diferentes categorías metafóricas. Tanto en el caso de las metáforas humanitarias (las de mayor representación) como en el de las sanitarias, alarmantes y de personificación, que son las cuatro únicas categorías que superan la decena de casos, el título es el epígrafe textual más recurrente, seguido de los sumarios. Se trata de un dato muy relevante ya que la presencia de las metáforas en estos epígrafes textuales manifiesta que el medio las sitúa en zonas destacadas. No pretende relegarlas a espacios en los que pueden pasar inadvertidas, como el cuerpo de la noticia, sino otorgarles la mayor visibilidad.

Las categorías más empleadas, es decir las voces humanitarias, sanitarias y alarmantes o apocalípticas son las más repartidas en diferentes ubicaciones, apareciendo en 6 y 5 epígrafes textuales distintos, respectivamente.

Tabla 2. Metáforas y epígrafes textuales en los que aparecen.

Fuente: Elaboración propia..

\begin{tabular}{|c|c|c|c|c|c|c|c|c|c|}
\hline & Alarmantes & Bélicas & Humanitarias & Sanitarias & Morales & Naturalización & Personificación & Plano General & TOTAL \\
\hline Título & 15 & 2 & 45 & 19 & 3 & 2 & 6 & 1 & 93 \\
\hline Antetítulo & 2 & & 4 & 1 & & & & & 7 \\
\hline Subtítulo & 1 & & 6 & 3 & 3 & & 2 & & 15 \\
\hline Sumario & 5 & 1 & 26 & 8 & 3 & 1 & 4 & & 48 \\
\hline Ladillo & 1 & & & & 1 & & & & 2 \\
\hline Pie de foto & & & 2 & & & 1 & & & 3 \\
\hline Destacado & & & 3 & 1 & & & & & 4 \\
\hline TOTAL & 24 & 3 & 86 & 32 & 10 & 4 & 12 & 1 & 172 \\
\hline
\end{tabular}

La voz metafórica más empleada es "rescate", utilizada hasta en 83 ocasiones, lo que supone que este vocablo acapara casi la mitad $(48.2 \%)$ de los 172 casos registrados. Los siguientes dos términos según la frecuencia de su empleo son "recortes" e "inyección" con 9 y 8 casos respectivamente, que pertenecen a la categoría de las voces metafóricas sanitarias, pues hacen referencia a los tratamientos a emplear para curar al enfermo, en este caso, el sistema económico. En la siguiente tabla se pueden consultar todas las voces metafóricas aparecidas, la categoría a la que pertenecen y el número de registros de cada una de ellas.

Tabla 3. Voces metafóricas: frecuencia y categorización. Fuente: Elaboración propia.

\begin{tabular}{|l|l|l|}
\hline \multicolumn{1}{|c|}{$\begin{array}{c}\text { VOZ METAFÓTICA (Y } \\
\text { SUS DERIVADOS) }\end{array}$} & \multicolumn{1}{|c|}{ CATEGORÍA } & NÚMERO DE REGISTROS \\
\hline Rescate. & Humanitarias. & 83 \\
\hline Recorte. & Sanitarias. & 9 \\
\hline Inyección. & Sanitarias. & 8 \\
\hline Desplomar. & Alarmantes o apocalípticas. & 6 \\
\hline Contagio. & Sanitarias. & 4 \\
\hline Da un respiro & Humanitarias. & 3 \\
\hline Golpe de oxígeno, Receta. & Sanitarias. & 3 \\
\hline Sacrificio. & Morales. & 3 \\
\hline Tormenta. & Naturalización. & 3 \\
\hline Relajar. & Personificación. & 3 \\
\hline
\end{tabular}




\begin{tabular}{|l|l|l|}
\hline $\begin{array}{l}\text { Bono basura, Corralito, Des- } \\
\text { peñarse, Hundirse y Jornada } \\
\text { negra. }\end{array}$ & Alarmantes o apocalípticas. & 2 \\
\hline Castigo, Juicio y Veredicto. & Morales. & 2 \\
\hline Dudas, Miedo. & Personificación. & 2 \\
\hline $\begin{array}{l}\text { Apocalipsis, Boquete, Des- } \\
\text { bocada, Emergencia, Fondo } \\
\text { de salvación, Fantasma del } \\
\text { rescate, Golpea y Tocar } \\
\text { fondo. }\end{array}$ & Alarmantes o apocalípticas. & 1 \\
\hline $\begin{array}{l}\text { Acoso, Ataque y Bomba } \\
\text { nuclear }\end{array}$ & Bélicas. & 1 \\
\hline $\begin{array}{l}\text { Activos tóxicos, Convulso, } \\
\text { Paracetamol financiero, San- } \\
\text { gría y Créditos tóxicos. }\end{array}$ & Sanitarias. & 1 \\
\hline Resurrección. & Morales. & 1 \\
\hline Furor. & Naturalización. & 1 \\
\hline $\begin{array}{l}\text { Apaciguar, Atribulada, Cal- } \\
\text { mar, Temor y Tranquilizar. }\end{array}$ & Personificación. & 1 \\
\hline Laberinto. & Plano general. & \\
\hline
\end{tabular}

En la tabla 3 se puede apreciar la diversidad de la riqueza expresiva empleada por el diario $\mathrm{La}$ Vanguardia ya que se han registrado hasta 45 voces metafóricas distintas. 24 de ellas aparecen en una única ocasión, mientras que las otras 21 se repiten, en mayor o menor medida. Esta reiteración en el uso de una metáfora concreta o el empleo de voces similares dentro de una misma categoría o temática (como las metáforas sanitarias) constata una tendencia del medio a decantarse por este tipo de recursos.

\section{Discusión}

Si bien la elección puntual de una metáfora puede no tener un significado más allá de una asignación accidental, el uso continuado de ciertas figuras y expresiones metafóricas durante un cierto periodo de tiempo, denota una tendencia a narrar los acontecimientos desde un determinado prisma. Cuando ese posicionamiento es patente en las manifestaciones periodísticas propias del género informativo y no aparece únicamente en el cuerpo de la noticia sino que se le otorga un lugar destacado (en el titular o en el sumario), la elección metafórica no parece tener nada de accidental.

Consideramos que un periodo de estudio mayor no aportaría un refuerzo sustancial a las conclusiones extraídas, pues el que ha sido analizado tiene ya un valor representativo, a la par que simbólico, y nos permite conocer el posicionamiento del medio. Cada periódico opta por narrar cualquier acontecimiento desde una determinada óptica. La gravedad y relevancia del fenómeno estudiado conlleva que sea de especial interés entender el enfoque elegido por el diario analizado. Parece evidente que, en este caso, la personificación del sistema económico como un paciente nos conduce hacia la aplicación de unas medidas humanitarias, de modo que no se hace necesario pedir responsabilidades o cuestionarnos el funcionamiento del sistema (Prieto-Pradas, 2013), puesto que se focaliza nuestra atención en lo prioritario: sanar al paciente. 
Un enfoque de la crisis que, en resumen, daría carta de naturaleza a un discurso que exime de cualquier tipo de responsabilidad sobre la misma al sistema económico. Un sistema económico del que, por otro lado, no podemos olvidarlo, los medios de comunicación forman parte, y que, en gran medida, como es el caso del diario analizado, pertenecen, utilizando la terminología del profesor José Luis Sampedro (2000: 70), a "los centros económicos dominantes".

\section{Conclusiones}

A En síntesis, a lo largo del análisis que hemos hecho de las piezas periodísticas publicadas por La Vanguardia, la Gran Recesión se convierte en una cuestión humanitaria cuando esta aparece representada, fundamentalmente, por la voz metafórica "rescate". Dicho de otra manera, el rescate del sistema bancario español se nos presenta como un asunto humanitario, como algo "benigno, caritativo, benéfico", "que mira o se refiere al bien del género humano" (Diccionario en línea de la RAE). Un "rescate" que es consecuencia de la personificación de un sistema económico al que se debe "dar un respiro" y que es tan vulnerable como el propio ser humano. Alguien tan vulnerable que sufre y padece enfermedades.

Bajo la categoría de metáforas sanitarias, la Gran Recesión fue presentada por La Vanguardia como una enfermedad cuyas causas ("créditos tóxicos", "contagio") y cuyos síntomas ("convulso" "sangría") son mostrados mediante expresiones que no muestran la etiología real de dicha dolencia. Además, presentando al sistema económico como un enfermo, se convierte a los componentes y las estructuras del mismo en víctimas de la propia recesión. Y así una economía plagada de "activos" y "créditos tóxicos" no tendrá más remedio que someterse a la "receta" de los "recortes", para que pueda finalmente ser curada.

La representación de la crisis convierte al sistema económico en un ser humano que no solo padece enfermedades, sino que también experimenta las emociones más básicas de este. Hablar de una economía "atribulada", de "temor", de "dudas", de "miedo" es representar la crisis, a través de las metáforas de personificación, como una consecuencia de la vulnerabilidad del sistema económico. Porque es hablar de un sistema económico que responde a las mismas emociones que son consustanciales al ser humano.

Por otro lado, las metáforas alarmantes o apocalípticas nos presentan la Gran Recesión como un hecho de extrema gravedad y de consecuencias impredecibles, cuando hablan de la misma como el "Apocalipsis". Ese fin del mundo al que hace referencia la Biblia y que en las páginas de La Vanguardia tiene forma de "corralito". Porque cómo no vamos a entender como el fin del mundo el hecho de no poder disponer de todos nuestros ahorros, de todo nuestro dinero, en una sociedad como la actual. O acaso no sería el fin del mundo pensar en una sociedad donde el dinero no circulara libremente. "Emergencia" o "jornada negra" son metáforas alarmantes o apocalípticas que, sin duda, evocan la imagen del fin de un mundo, el mundo que conocemos.

Por su parte, las metáforas de naturalización, aquellas que presentan la Gran Recesión como "un fenómeno de la naturaleza", inciden en la cualidad de inevitabilidad de la misma, puesto que los sucesos meteorológicos o naturales ("tormenta") no pueden evitarse, aunque algunos puedan llegar a preverse. Unos sucesos desencadenados por una naturaleza, a veces incluso por la propia acción del hombre (estos sí serían evitables), que actúa con "furor", y cuyas consecuencias pueden ser tan alarmantes o apocalípticas, como las metáforas utilizadas en el relato mediático de estos hechos. 
Junto a las categorías ya comentadas, las metáforas bélicas, aquellas que cuentan la crisis con términos propios de un conflicto bélico, contribuyen también a remarcar la gravedad de dicho suceso. Puesto que se nos presenta como el resultado de una guerra de agresión que, en las páginas de La Vanguardia, aparece reflejado como un "ataque" o "acoso", lo que supone que hay un agresor, los mercados, y un agredido, el sistema económico. En cualquier caso, como en cualquier conflicto bélico, todos seríamos víctimas de esta guerra. Algo que nos llevaría, por otra parte, a la socialización de los efectos de la recesión, ya que todos seríamos víctimas de la misma.

Y llegamos así a las metáforas morales, las que, al representar la crisis como el resultado de la sentencia del juicio moral al que hemos sido sometidos todos por haber vivido por encima de nuestras posibilidades, evocan la imagen de la recesión como la justa consecuencia que deben sufrir quienes han infringido las leyes de los mercados y deben hacer un "sacrificio" que permita expiar sus culpas. Una expiación que sería el inevitable pago para una posterior "resurrección" de la economía.

Por otra parte, La Vanguardia ha generado este discurso sobre la Gran Recesión a través, principalmente, de sus páginas de información. Es más, hay muy pocas metáforas en sus páginas de opinión. Un hecho llamativo, sin duda, ya que las metáforas contienen opinión, conllevan una carga ideológica, y aparecen en un espacio donde aquella no debería ocupar ni una sola línea. Estamos hablando, pues, de una opinión disfrazada, en este caso de metáfora, en las páginas reservadas a la información. Se repite el mismo patrón apuntado por Martín Sáez (2017) en su análisis de los diarios El País y El Mundo, si bien en este último el recurso metafórico tenía un menor peso.

Esta opinión disfrazada de metáfora aparece en la mayoría de las informaciones, columnas y editoriales analizados de forma destacada, ya que dicha figura retórica está presente, principalmente, en el titular. Más de la mitad de las expresiones metafóricas tienen forma de titulares, que son los epígrafes que "expresan la información más importante, más pertinente o más 'sorprendente' del relato de la noticia", interpretando "los acontecimientos o acciones desde el punto de vista del periodista (o del periódico)" (Van Dijk, 1983: 85-86).

Podemos concluir, en definitiva, que el diario La Vanguardia se apoyó en una narrativa metafórica, a la hora de hablar sobre la Gran Recesión, que presenta al sistema económico español como un paciente al que era necesario sanar. Su audiencia recibe así un mensaje editorializante sobre dicho suceso al elegir el diario unas determinadas metáforas en detrimento de otras.

\section{Bibliografía}

Bardin, L. (1996). Análisis de contenido. Madrid: Akal Ediciones.

Bauman, Z. (2013). Modernidad líquida. Buenos Aires: Fondo de Cultura Económica.

Beck, U. (1996). Teoría de la sociedad del riesgo. En Beriain, J. (coord.), Las consecuencias perversas de la modernidad (pp. 201-222). Barcelona: Anthropos.

Bustos, E. de (2014). Metáfora y argumentación: teoría y práctica. Madrid: Cátedra. 
Casero, A. (2008). Modelos de relación entre periodistas y políticos: la perspectiva de la negociación constante. Estudios sobre el mensaje periodístico, 14, 111-128. Recuperado de http:// revistas.ucm.es/index.php/ESMP/article/view/ESMP0808110111A/11830

Diccionario de la Real Academia Española (DRAE). (2012). Consultado en http://rae.es/recursos/ diccionarios/drae

Dijk, T. A. van (1983). Estructuras textuales de las noticias en prensa. Análisi. Quaderns de comunicació i cultura, 7-8, 77-105.

Dijk, T. A. van (2009). Discurso y poder. Barcelona: Gedisa.

Foucault, M. (2000). Un diálogo sobre el poder y otras conversaciones. Madrid: Alianza Editorial.

Freud, S. (2015). Psicología de las masas. Madrid: Alianza Editorial.

Galán, J. (2001). Aprender a ver los diarios: elementos visuales en la composición de las publicaciones periódicas. Cuadernos de cultura escrita, 1, 203-220. Recuperado de http://hdl.handle. net/10016/2268

Gallego, F. J. (2013). Sociometafórica del secreto. Aposta, 57, 1-27. Recuperado de http://www. apostadigital.com/revistav3/hemeroteca/figallego1.pdf

Gaspar, A. e Ibeas, N. (2015). El discurso institucional en tiempos de crisis: análisis del Mensaje de Navidad de Su Majestad el Rey. Zer, 20(38), 31-48. http://www.ehu.eus/ojs/index.php/Zer/article/ view/14778/13058

Giddens, A. (2000). Sociologia. Madrid: Alianza Editorial.

Herrscher, R. (2012). Periodismo narrativo. Cómo contar la realidad con las armas de la literatura. Barcelona: Publicacions i edicions de la Universitat de Barcelona.

Igartua, J.J. (2006). Métodos cuantitativos de investigación en comunicación. Barcelona: Bosch.

Krippendorff, K. (1990). Metodología de análisis de contenido: Teoría y práctica. Barcelona: Paidós.

Lakoff, G. y Johnson, M. (2012). Metáforas de la vida cotidiana. Madrid: Cátedra.

Lizcano, E. (1999). La metáfora como analizador social. Empiria, 2, 29-60. doi: 10.5944/ empiria.2.1999.709

Lizcano, E. (2009). La economía como ideología. Un análisis socio-metafórico de los discursos sobre 'la crisis'. Revista de ciencias sociales, 16, 85-102. Recuperado de: http://www.unq.edu.ar/advf/ documentos/594031078291a.pdf 
Luhmann, N. (2007). La realidad de los medios de masas. Barcelona: Anthropos.

Martín Sáez, J. L. (2015). Sociedad del riesgo y prima de riesgo. El discurso mediático sobre la inevitabilidad de la crisis: un estudio sobre El Mundo y El País. (Tesis doctoral. Universidad Rey Juan Carlos, Fuenlabrada).

Martín Sáez, J. L. (2017). El discurso mediático sobre la inevitabilidad de la crisis: una explicación metafórica de la economía. Estudios sobre el mensaje periodístico, 23 (2), 909-924. doi: $10.5209 /$ $\underline{\text { ESMP.58023 }}$

McCloskey, D. N. (1990). Storytelling in economics. En Nash, C. (ed.), Narrative in culture: the uses of storytelling in the sciences, philosophy and literature (pp. 5-22). London: Routledge. Recuperado de: http://www.deirdremccloskey.com/docs/pdf/Article_125.pdf

Millán, J. A. y Narotzky, S. (2012). Introducción. En Lakoff, G. y Johnson, M., Metáforas de la vida cotidiana (pp. 11-25). Madrid: Cátedra.

Montes Vozmediano, M. (2013). Análisis del diseño gráfico de las revistas de moda en España, desde una perspectiva cromática. (Tesis doctoral. Universidad Rey Juan Carlos, Fuenlabrada). doi: 10.13140/ rg.2.1.4387.5686/1

Oficina de Justificación de la Difusión (OJD). (2018). Consultado en https://www.ojd.es/buscador

Prieto-Pradas, L. F. (2013). Tratamiento informativo del inicio de la crisis económica mundial de 2008 según la prensa nacional. Miguel Hernández Communication Journal, 6(44), 113-132. doi: 10.21134/mhcj.v1i4.6

Roig, M. (2008). Prólogo: soy ciego y hoy comienza la primavera. En Salmon, C., Storytelling. La máquina de fabricar historias y formatear las mentes. Barcelona: Ediciones Península.

Sampedro, J. L. (2002): El mercado y la globalización. Barcelona: Destino.

Serrano, P. (2009). Desinformación. Cómo los medios ocultan información. Barcelona: Península.

Uribe, C., Arimany, N., \& Sabata-Aliberch, A. (2016). Comunicación en período de crisis y puertas giratorias en el caso Abengoa: análisis en prensa económica. Obra digital: revista de comunicación, 11, 101-115. Recuperado de http://revistesdigitals.uvic.cat/index.php/obradigital/article/ view/97/96

Valkenburg, P. M., Semetko, H. A. y De Vreese, C. H. (1999). The effects of news frames on readers' thougts and recall. Communication Research, 26(5), 550-569. Recuperado de: https://www. academia.edu/7703232/The Effects of News Frames on Readers Thoughts and Recall?auto=download 
MHCJ no 10 (1) | Año 2019 - Artículo no 4 (139) - Páginas 83 a 99 - mhjournal.org

\section{(c) ()}

Licencia Creative Commons

Miguel Hernández Communication Journal

mhjournal.org

\section{Cómo citar este texto:}

José Luis Martín Sáez, Manuel Montes Vozmediano (2019): Un análisis socio-metafórico del discurso mediático de la Gran Recesión en La Vanguardia, en Miguel Hernández Communication Journal, nº10 (1), pp. 83 a 99. Universidad Miguel Hernández, UMH (Elche-Alicante). DOI: http://dx.doi.org/10.21134/mhci.v10i0.276 